\title{
Effective health information systems for delivering the Sustainable Development Goals and the universal health coverage agenda
}

\author{
Arash Rashidian
}

${ }^{1}$ Director of Science, Information and Dissemination, WHO Regional Office for the Eastern Mediterranean, Cairo, Egypt. (Correspondence to: Arash Rashidian: rashidiana@who.int).

Citation: Rashidian A. Effective health information systems for delivering the Sustainable Development Goals and the universal health coverage agenda. East Mediterr Health J. 2019;25(12):849-851. https://doi.org/10.26719/2019.25.12.849

Universal health coverage (UHC) and the healthrelated Sustainable Development Goals (SGDs) cannot be achieved without the appropriate measurement and monitoring mechanisms (1). At the global level, extensive attention is given to mechanisms that focus on measuring and reporting the status of SDG indicators, to help in shaping global priorities, and to steer political will and leverage for action at the national level. National decision-making, however, goes beyond accepting UHC and the SGDs as targets: it should also include specific policies that improve access to health services and health outcomes. The importance of such detail has been well documented before, including in the case of a major global policy for child health (2).

Unfortunately, most global comparisons and the summary indices developed from them are not sensitive enough to national policy change and may not help countries in this direction (3). It is hard to imagine that the phenomenal country successes witnessed in the postAlma Ata primary health care implementation era would have been as successful as they were, if they had relied on global estimation and reporting processes as sources of data (4). The pivotal role of collecting data on a small set of locally-relevant and policy-oriented indicators, using the paper-based approaches of the time, in the success of primary health care implementation plans is well documented (5). The same is true today; countries cannot reach UHC objectives and the SDGs by relying only on international comparisons and estimation processes.

National health information systems that respond to national needs and are efficient are required. Such national systems provide the locally-relevant information from routine sources (e.g. civil registration and vital statistics systems and health care facilities), as well as from household surveys and census surveys, that is required for national planning and monitoring of implementation. The results framework of WHO's Thirteenth General Programme of Work, 2019-2023, is intended as an overarching approach to data and information for health (6). It is a WHO commitment that its work with countries, alongside other United Nations agencies and partners, results in improved health outcomes (7). The framework includes a set of key indicators that complements the SDG agenda, with a further focus on the triple objectives of improving UHC, enhancing safety and increasing population health (7). Alongside this, it includes a core set of activities to improve national data systems so that globally comparable data are valid, timely and reliable, while countries benefit from the availability of the information needed for national and subnational planning, policy implementation and monitoring of health outcomes and equity objectives (8).

In countries of the Eastern Mediterranean Region, WHO work in this area is within the domains outlined in Table 1. The core health indicators agenda (including the health-related SGD indicators) (9), reflects the global approach to regular reporting of comparable data from countries. The regional civil registration and vital statistics systems agenda is a key initiative in response to the many limitations of the current systems in most countries of the Region, and is focused on timely and complete registration of deaths, and accurate certification of the cause of death (10). Regarding surveys, WHO supported the conduct of its first pilot of the new World Health Survey approach (WHS+) in 2016 in Tunisia and a model national survey plan has been developed for use by countries. This was a response to the observation that in many countries surveys were done as a response to global or donor requests rather than national needs, and that many surveys with considerable overlap were conducted too close to each other, while several years might pass with no national household survey undertaken in the country.

In terms of routine health information system development, regional initiatives have been developed to assess national health information systems (followed by strategy development), and a programme of capacity-building for countries in need of District Health Information Software 2 (DHIS-2) package implementation has been carried out (11). Recently, the agenda has been expanded to include the Primary Health Care Measurement and Improvement Initiative (PHCMI), and a similar approach is being developed for hospital information system support (12). Following the release of the 11th Revision of the International Classification of Diseases (ICD-11), extensive work has been undertaken to support its adoption in countries as the basic standard for data reporting on mortality and morbidity. This work is now being expanded to encompass the International Classification of Health Interventions (ICHI) due to be released in 2020, and technical support is being provided to ensure that all health-related data systems are based on these global approaches and WHO-sanctioned standards for health data.

While the Region faces many structural limitations on national data improvement, these programmes that 
are based on strong national political commitment and country demand have resulted in key improvements to data systems and coverage (13). A few countries of the Region are experiencing emergencies that negatively affect their national systems for health data, while massively increasing the need for data generation. While data systems for emergency settings are beyond the scope of this short article, they are an important part of
WHO's work in this area (14). In the end, these initiatives are as successful as the commitment given to them on the ground. Health information systems and the data generated by the estimation process have important comparative value, but their best use is when they can equip policy-makers and managers with the evidence and knowledge they need for decision-making (15). This is the goal that we are striving towards.

\section{Table 1 WHO initiatives for improving national information}

\section{WHO strategic areas of support for improving availability and use of health data}

Global comparison of nationally representative indicators, and enhancing visibility and use of national and subnational indicators

Enhancing national health information systems and infrastructure, including birth and death registration and certification of cause of death
SDG monitoring and indicators WHO Impact Framework Global Health Observatory

SCORE assessments and package of health information system initiatives Support for DHIS-2 development
National capacity-building and support for household surveys, and subnational and equityoriented analyses
World Health Survey (WHS+)

Health equity assessment toolkit (HEAT

Plus)

WHO STEPwise approach to Surveillance

(STEPS) surveys

Service availability and readiness assessment (SARA) surveys

Disease-specific surveys

Enhancing national health information systems and infrastructure, including birth and death registration and certification of cause of death
WHO family of international classifications, including ICD11, International Classification of Functioning, Disability and Health (ICF) and ICHI

Current WHO initiatives for data
systems in the Eastern Mediterranean
Region
Regional SDGs and core-indicator
reporting
Regional Health Observatory
National civil registration and vital
statistics system assessments and
strategies
Comprehensive national health
information system assessment
Regional SCORE review
DHIS-2 implementation in target countries
PHCMI analysis and reporting support
WHS+ global pilots
Developing national household survey
plans
SARA survey conduct and analysis
Support for other surveys
Support for national health observatories

systems in the Eastern Mediterranean Region

Regional SDGs and core-indicato

National civil registration and vital statistics system assessments and

sive national health DHIS-2 implementation in target countries PHCMI analysis and reporting support plans

SARA survey conduct and analysi Support for other surveys

Support for national health observatories

\section{References}

1. Health in 2015: from MDGs to SDGs, Sustainable Development Goals. Geneva: World Health Organization; 2015.

2. Ahmed HM, Mitchell M, Hedt B. National implementation of Integrated Management of Childhood Illness (IMCI): policy constraints and strategies. Health Policy. 2010;96(2):128-133. doi:10.1016/j.healthpol.2010.01.013.

3. AbouZahr C, Boerma T, Hogan D. Global estimates of country health indicators: useful, unnecessary, inevitable? Glob Health Action. 2017;10(sup1):1290370. doi:10.1080/16549716.2017.1290370.

4. Kruk ME, Porignon D, Rockers PC, Van Lerberghe W. The contribution of primary care to health and health systems in lowand middle-income countries: a critical review of major primary care initiatives. Social Sci Med. 2010;70:904-911. doi:10.1016/j. socscimed.2009.11.025.

5. Mehryar AH, Naghavi M, Ahmad-Nia S, Kazemipour S. Vital horoscope: longitudinal data collection in the Iranian primary health care system. Asia-Pacific Population Journal. 2008:23(3):55-74. doi:10.18356/ea6aec90-en

6. Thirteenth general programme of work, 2019-2023. Results framework: an update. Geneva: World Health Organization: 2019.

7. Mahjour J, Mirza Z, Rashidian A, Atta H, Hajjeh R, Thieren M, El-Adawy M, Hammerich A, Al-Yousfi A, Haka RB, El Khodary $\mathrm{H}$. "Promote health, keep the world safe, serve the vulnerable in the Eastern Mediterranean Region. East Mediterr Health J. 2018:24(4):323-324. doi:10.26719/2018.24.4.323.

8. SCORE to reach your health goals: a technical package to strengthen country health data (working document). Geneva: World Health Organization: 2018.

9. Alwan A, Ali M, Aly E, Badr A, Doctor H, Mandil A, et al. Strengthening national health information systems: challenges and response. East Mediterr Health J. 2016;22(11):840-850. 
10. Resolution EM/RC60/R.7. Regional strategy for the improvement of civil registration and vital statistics systems 2014-2019. Cairo: WHO Regional Office for the Eastern Mediterranean; 2013 (http://applications.emro.who.int/docs/RC6o_Resolutions_2013_ R7_15140_EN.pdf?ua=1, accessed 22 December 2019).

11. Sahay S, Rashidian A, Doctor HV. Challenges and opportunities of using DHIS2 to strengthen health information systems in the Eastern Mediterranean Region: A regional approach. Electronic Journal of Information Systems in Developing Countries. 2019. https://doi.org/10.1002/isd2.12108 (https://onlinelibrary.wiley.com/doi/full/10.1002/isd2.12108, accessed 22 December 2019).

12. Rashidian A, Doctor H, Aly E, Badr A. Health information in primary care and family practice: concept, status and a vision for the Eastern Mediterranean Region. In: Salah H, Kidd M, editors. Family practice in the Eastern Mediterranean Region: universal health coverage and quality primary care. Boca Raton FL: CRC Press; 2019:57-73.

13. Eastern Mediterranean Region: framework for health information systems and core indicators for monitoring health situation and health system performance 2018. Cairo: WHO Regional Office for the Eastern Mediterranean; 2018 (https://rho.emro.who. int/sites/default/files/booklets/EMR-HIS-and-core-indicators-2018.pdf\%20, accessed 22 December 2019).

14. Samhouri D, Ijaz K, Rashidian A, Chungong S, Flahault A, Babich SM, Mahjour J. Analysis of Joint External Evaluations in the WHO Eastern Mediterranean Region. East Mediterr Health J. 2018;24(5):477-487. doi: 10.26719/2018.24.5.477.

15. Rashidian A, Mandil A, Mahjour J. Improving evidence informed policy-making for health in the Eastern Mediterranean Region. East Mediterr Health J. 2017:23(12):793-794. doi:10.26719/2017.23.10.793. 